\title{
Erratum: Computerised prescribing for safer medication ordering: still a work in progress
}

Schiff GD, Hickman T-TT, Volk LA, et al. Computerised prescribing for safer medication ordering: still a work in progress. BMJ Qual Saf 2016;25:315-9. doi:10.1136/bmjqs-2015-004677

The original article is missing several acknowledgements. The amended acknowledgements statement is as below:

The authors would like to acknowledge contributions of FDA staff: Carol Holquist, RPh, Office of Regulatory Operations, Office of Generic Drugs; Kendra Worthy PharmD, Division of Medication Error Prevention and Analysis (DMEPA), Office of Medication Error Prevention and Risk Management (OMEPRM), Office of Surveillance and Epidemiology (OSE), Center for Drug Evaluation and Research (CDER); and Vicky Borders-Hemphill PharmD, DMEPA, OMEPRM, OSE, CDER, for their scientific support. In addition, the authors would like to especially thank FDA staff: Kellie Taylor, PharmD, MPH, DMEPA, OMEPERM, OSE, CDER, Irene Chan, PharmD, BCPS, DMEPA, OMEPERM, OSE, CDER, and Colleen Brennan, RPH, DMEPA, OMEPERM, OSE, CDER for their thoughtful contributions to the science and manuscript development, the authors also thank Katrina Garry, Denise Jones, and Rita Noel, OSE Contracts Management Team, for their administrative support.

BMJ Qual Saf 2017;26:429. doi:10.1136/bmjqs-2015-004677corr1 